\title{
A Linear Parabolic Trough Solar Collector Performance Model
}

\author{
Ming Qu \\ $\mathrm{PhD}$. Student \\ David H. Archer \\ Professor of Engineering \\ Sophie V. Masson \\ School of Architecture \\ Research Engineer \\ Center for Building Performance and Diagnostics \\ Carnegie Mellon University \\ Pittsburgh, PA USA \\ mqu@andrew.cmu.edu
}

\begin{abstract}
A performance model has been programmed for solar thermal collector based on a linear, tracking parabolic trough reflector focused on a surface-treated metallic pipe receiver enclosed in an evacuated transparent tube: a Parabolic Trough Solar Collector (PTSC). This steady state, single dimensional model comprises the fundamental radiative and convective heat transfer and mass and energy balance relations programmed in the Engineering Equation Solver, EES. It considers the effects of solar intensity and incident angle, collector dimensions, material properties, fluid properties, ambient conditions, and operating conditions on the performance of the collector: the PTSC.

Typical performance calculations show that when hot-water at $165 \mathrm{C}$ flows through a $6 \mathrm{~m}$ by $2.3 \mathrm{~m}$ PTSC with $900 \mathrm{w} / \mathrm{m}^{\wedge} 2$ solar insulation and 0 incident angle, the estimated collector efficiency is about 55\% The model predictions will be confirmed by the operation of PTSCs now being installed at Carnegie Mellon.
\end{abstract}

\section{INTRODUCTION}

\subsection{IW Solar Heating And Cooling System}

A R\&D project of innovative solar heating and cooling systems (SHCS) is developing for Intelligent Workplace (IW) at Carnegie Mellon University in Pittsburgh. This system will provide heating and cooling through the use of renewable energy, like solar, directly in absorption refrigerant cycle with control of the temperature and humidity of the fresh air supply for the building.

\subsection{Parabolic Trough Solar Collector}

The PTSC, installed at CMU, is from BROAD Air Conditioning Co. Ltd in China, which is the largest absorption chiller manufacturer in the world. The PTSC, shown in Figure2, includes a parabolic reflective mirror, receiver pipe, steel support structure and a single-axis drive mechanism.

It tracks the sun about single axis during the day. Once the sun light strikes on the PTSC's reflective mirror, it is reflected to the PTSC's receiver tube. The heat transfer fluid flows from one end of the receiver tube to another end to convert solar energy into thermal energy, which is used to drive an absorption chiller for space heating and cooling.

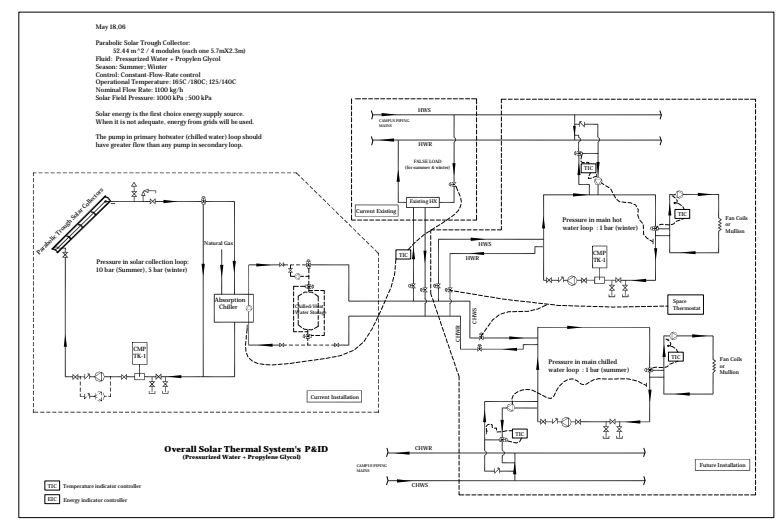

Fig. 1 IW solar heating and cooling system

\subsection{EES Model}

In order to understand PTSC and carry out system design and predict system overall performance, it is a necessary to build a mathematical model for the PTSC.

The SHCS, indicated in Figure 1, mainly consists of $52.44 \mathrm{~m}^{2}$ single-axis parabolic trough solar collectors (PTSC), a 16kW 


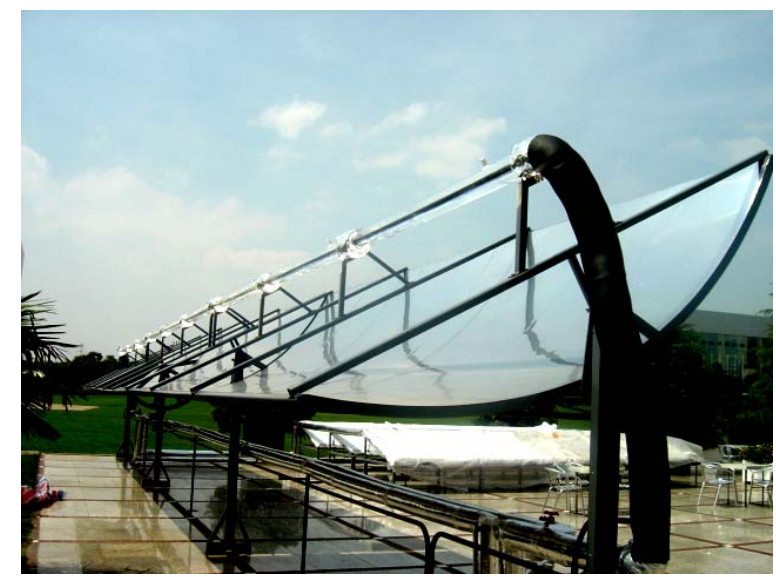

Fig 2 Broad Ptscs

The software used for modeling is engineering equation solver (EES), developed by the University of Wisconsin Madison. The basic function provided by EES is the solution of a set of algebraic equations. There are two major differences between EES and existing numerical equation-solving programs. First, EES automatically identifies and groups equations that must be solved simultaneously. Second, EES provides many built-in mathematical and thermophysical property functions useful for engineering calculations.

\section{MODEL DESCRIPTION}

\subsection{PTSC Energy Gain And Losses}

The primary function of the model is to predict solar collector efficiency that is the thermal energy output of PTSC. Normally collectors with geometric concentration ratios of 10 or greater, like PTSC, ypically are capable of using only the beam insolation. Any diffuse insolation is usually lost to the concentrator since the light must strike the reflector at perpendicular angle to the aperture surface in order to be reflected to a given focus point.

Reflection losses, one part of optical losses reduce the amount of insolation arriving at the receiver by focusing errors, tracking errors, and errors in the alignment of the mirror surface. Since these losses are hardly to predict by using scientific equation, they, due to reflection errors, are taken into account by a reflection efficiency, which can be obtained by experimental data or empirical basis.
Besides of reflection losses, optical losses include the losses related to the physical properties of glass envelope, coating of absorber, and absorber tube.

Once the solar insolation has been absorbed by the receiver, the thermal losses are only left contributions to the collector's efficiency. The model created is to predict PTSC performance by evaluating thermal losses involved in PTSC's receiver tube.

\subsection{General Description Of Model}

The developed PTSC model is a steady-state model and based on the energy balance and heat transfer mechanism within PTSC's receiver tube. It could calculate the fraction of the incident solar energy recovered in the fluid circulating through the pipe receiver, the detail thermal losses from collector, the pressure drop of that fluid over the receiver, and the temperatures of various collector components and of the fluid throughout the receiver under different conditions like include direct normal solar irradiation, incidence angle, and wind speed.

In addition, the model could be used for optimizing PTSC design by varying the size of receiver tube, the size of glass envelope, receiver tube material, coating material and so forth.

\subsection{Theory Of Solar Collector}

A solar collector, actually, is a special kind of heat exchanger that transfers solar radiation energy into heat. In the solar collector, energy transfer is from a distant source of radiant energy to a fluid. The typical PTSC can be employed for application requiring energy delivery at medium or high temperatures, up to perhaps $300 \mathrm{C}$ above ambient temperature. (John A. Duffie 1980)

\subsection{General Description Of The Receiver Tube}

The PTSC's receiver tube, as shown in Figure 3, is located at the focus line of parabolic reflective surface, with means of transferring the absorbed solar energy to a fluid. The inside of receiver tube is the absorber tube coated with selective blackened nickel. This coating has high 
absorption of short length solar radiation and low emissivity for long wave energy spectrum to reduce thermal radiation losses. The absorber tube is contained with glass, which maintains good strength and transmittance under high temperatures. The outside glass envelope transparent to solar radiation over the solar absorber surface that reduces convection and radiation losses to the atmosphere;

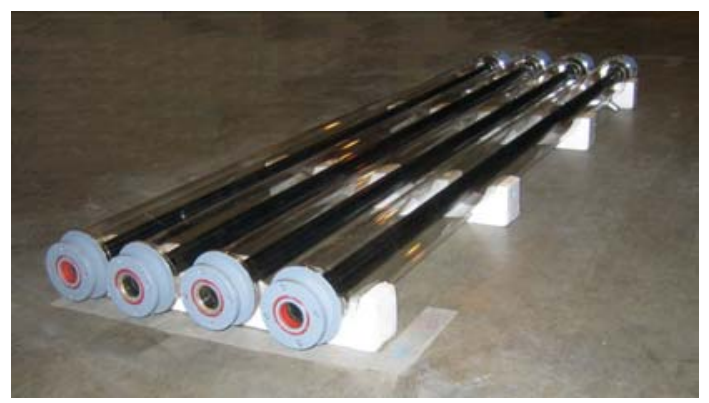

Fig. 3 the absorber tube

The annulus gap between absorber tube and glass envelope of BROAD PTSC is vacuumed in order to reduce conduction and convection between absorber and glass envelope.

\subsection{The Energy Balance}

In a steady state, the performance of a PTSC is described by an energy balance that indicates the distribution of incident solar energy into useful energy gain, thermal losses, and optical losses. The solar radiation absorbed by the receiver, $\dot{Q}_{a b s}$, on an hourly basis is equal to the multiply of direct incident solar radiation and the optical efficiency, as shown in equation 1 . The optical efficiency, $\eta_{\text {opt }}$ of a collector could be identified by the equation 2 , where $\mathrm{A}$ is the effective area ratio. The thermal loss from the collector to the surroundings is calculated by considerable detail heat transfer equations here. The hourly useful energy output of a PTSC is then the difference between the absorbed solar radiation and the thermal loss as shown in equation 3. Equation 3 is an energy rate equation in $\mathrm{W}$, when $I_{d n}$ is expressed in $\mathrm{W} / \mathrm{m}^{\wedge} 2$.

A measure of collector performance is the collection efficiency, defined as the ratio of collector useful gain to the direct normal incident solar energy on the
PTSC aperture area over some special time period, as shown in equation 4.

$\dot{Q}_{a b s}=A_{a} \eta_{o p t} I_{d n}$

$\eta_{o p t}=r^{*} \tau_{g} * \alpha_{r}^{*} A^{*} \eta_{o p^{\prime}}$

$\dot{Q}_{\text {out }}=\dot{Q}_{a b s}-\dot{Q}_{\text {thermalloss }}$

$\eta=\frac{\int Q_{u} d \tau}{A_{a} \int I_{d n} d \tau}$

When the solar radiation (red color arrows in Figure 4 , calculated by equation 5 ) is absorbed by glass envelope and the absorber tube, the energy loss through glass envelope and support structure is the results of convection and radiation from glass to surrounding and conduction between the absorber and support structure, respectively (purple color arrows in Figure 4, calculated by equation 6. .).

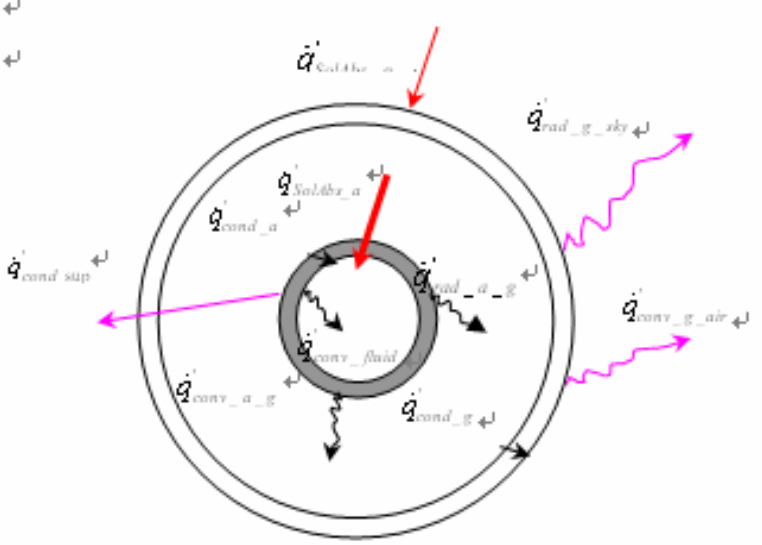

Fig. 4 energy components in an absorber tube

$$
\begin{aligned}
& \dot{q}_{\text {SolAbs }}^{\prime}=\dot{q}_{\text {SolAbs_g }}^{\prime}+\dot{q}_{\text {SolAbs_a }}^{\prime}(5) \\
& \dot{q}_{\text {thermalloss }}^{\prime}=\dot{q}_{\text {rad_g_sky }}^{\prime}+\dot{q}_{\text {conv_g_air }}^{\prime}+\dot{q}_{\text {cond_sup }}^{\prime}(6)
\end{aligned}
$$

For the outer surface of glass, the heat gain from solar and glass by conduction is equal to the heat losses from glass outside surface to ambient by means of convection and radiation, indicated in equation 7 . 
$\dot{q}_{\text {SolAbs_g }}^{\prime}+\dot{q}_{\text {cond_g }}^{\prime}=\dot{q}_{\text {conv_g_air }}^{\prime}+\dot{q}_{\text {rad_g_s }}^{\prime}{ }_{\text {sky }}$

For the inner surface of glass, the income heat is gain from absorber outer surface to inner surface of glass by radiation and convection. It is equal to the heat loss by means of the conduction through glass as shown in equation 8 .

$\dot{q}_{\text {conv_a_g }}^{\prime}+\dot{q}_{\text {rad_a_g }}^{\prime}=\dot{q}_{\text {cond } \_g}^{\prime}$

For the outer surface of the absorber, the heat directly gain from solar is equal to the heat transferred to glass envelop by means of radiation and convection, to support structure by conduction, and to the absorber by conduction, as shown in equation 9. The heat conducted to absorber is equal to the heat transferred by convection from absorber to heat transfer fluid shown in equation 10 .

$$
\begin{aligned}
& \dot{q}_{\text {SolAbs_a }}^{\prime}=\dot{q}_{\text {conv_a }}^{\prime}+\dot{q}_{\text {rad_a }}^{\prime}+\dot{q}_{\text {cond_a }}^{\prime}+\dot{q}_{\text {cond_bracket }}^{\prime} \\
& \dot{q}_{\text {cond_a }}^{\prime}=\dot{q}_{\text {conv_fluid }}^{\prime}
\end{aligned}
$$

Therefore, the PTSC efficiency can be calculated by equation 11 .

$\eta=\frac{\dot{q}_{\text {SolAbs }}^{\prime}-\dot{q}_{\text {thermalloss }}^{\prime}}{I_{d n} * A_{a}}$

In equation 5-11, dotted variables indicate rates and the prime indicates per unit length of absorber tube.

\subsection{Temperature Distribution in PTSC}

Although the detail analysis of a PTSC is a complicated problem, a relative simple heat transfer analysis could yield very useful results. They are the important variables, how they are related, and how they affect the performance of a solar collector. To appreciate the heat transfer model of PTSC, the temperature distribution within the receiver tube should be understood as shown in Figure 5. The energy transferred to the fluid will heat up the fluid causing a temperature gradient to exist in the direction of flow. At any location $y$, the general temperature distribution in $\mathrm{x}$ direction is as shown in middle of Figure 5, and at any location $\mathrm{x}$, the temperature distribution in the y looks like the right figure in Figure 5.

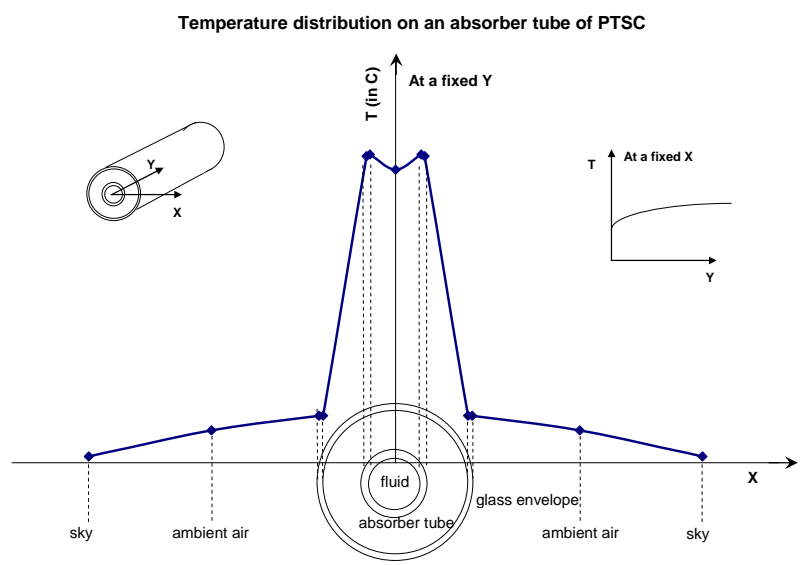

Fig. 5 temperature distribution of an absorber tube

To mathematically model the PTSC heat transfer, a number of simplifying assumption can be made to lay the foundation without obscuring the physical situation. These important assumptions are as follows:

1.PTSC performance is steady-state. (SS model)

2.There is a negligible temperature drop along the parabolic trough solar collector. (Onedimensional model)

3.The sky is considered as a blackbody for longwavelength radiation at an equivalent sky temperature.

4.Temperature gradients around absorber tube and glass envelope are neglected.

5.Shading effect of the absorber tube is negligible.

6.Dust and dirt on the PTSC are negligible.

\subsection{PTSC Heat Transfer}

The thermal network for the receiver tube of PTSC is shown in Figure 6. The related variables in equation 5-11 and in figure 6 are great associated. 
Table 1 includes all of major variable definitions and equations used in model.

Additionally, the model also included the calculation of piping performance. Therefore, users can use it to select pump and make decision on pipe size and insulation.

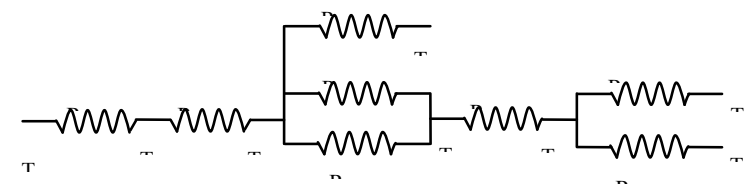

Fig. 6 the thermal network

\subsection{Interface}

The developed EES model calculates the performance of parabolic trough solar collector (PTSC) and related piping system. It deals with the thermo-physical properties of the PTSC receiver, the heat transfer fluid flowing through PTSC and the piping in the solar collection loop. The given parameters include direct normal radiation, wind speed, ambient temperature, geometric configuration and material of PTSC receiver tube, fluid flow rate and inlet temperature, as shown on the left part of Figure 7.

\section{MODEL RESULTS AND ANALYSIS}

\subsection{Results}

The calculation results include the temperature, pressure and properties of heat transfer fluid, efficiency of PTSC, the heat and pressure losses throughout the system. Figure 7 shows one of the model calculation results under these conditions. The hot water, at $165^{\circ} \mathrm{C}$ under pressure to prevent boiling, flows into 4 PTSC modules in series at $1200 \mathrm{~kg} / \mathrm{H}$; $800 \mathrm{~W} / \mathrm{m}^{\wedge} 2$ direct normal solar radiation is reflected on a $38 \mathrm{~mm}$ absorber tube located at the focus line of PTSC, whose outside surface is coated with selective blackened nickel. The solar piping is made of carbon steel wearing a $2 \frac{1}{2}$ fiberglass insulation jacket. Both the supply piping and the return piping total are 85 meter long.
As a result, the efficiency of PTSC is 0.5529 . The solar energy that can be delivered by PTSC is $1017 \mathrm{~W} / \mathrm{m}$. The outlet temperature of PTSC is $181^{\circ} \mathrm{C}$ and the total solar energy leaving collectors is 23.19 $\mathrm{kW}$. The heat loss through piping is $1.37 \mathrm{~kW}$. In terms of pressure, the pressure drop along PTSC is $1.055 \mathrm{kPa}$ and along piping is $2.089 \mathrm{kPa}$, so that the overall solar energy entering chiller is $21.82 \mathrm{~kW}$ and the total pressure drop is $3.144 \mathrm{kPa}$.

\subsection{Thermal Losses}

The thermal losses from the collector receiver are functions of operating temperature. The thermal losses through PTSC are changed in different ways depending on the receiver's configuration and operational conditions. As shown in Figure 8, among three losses: conduction, convection and radiation, the convection loss from absorb tube to supporting structures is the largest; the next is the radiation loss from glass envelope to ambient air; the relative smaller is the convection loss from glass envelope to ambient air.

The thermal losses are always existing (if there is a temperature difference between receiver and ambient) whenever solar radiation is available or not. Figure 9 shows the thermal losses with sun and no sun. The thermal loss for vacuum receiver has the same trend with sun or no sun. The reason for the higher thermal loss with sun is that solar flux heats the solar collector to a higher temperature, which is related to greater thermal losses.

In order to understand the PTSC performance, several sets of calculations were carried out by various operating temperature, flow type, flow rate, and different direct normal solar radiation, incident angle, wind speed and so forth.

\subsection{PTSC Efficiency And Operating Temperature}

When the operating temperature increases, the temperature of collector of collector has enhanced. The thermal losses to ambient and supporting structures are 
Tab. 1 Equations in the PTSC model

\begin{tabular}{|c|c|c|c|c|c|}
\hline Heat Name & HT type & From & To & Heat calculation & Equation reference \\
\hline$\dot{q}_{\text {SolAbs_g }}^{\prime}$ & & $\begin{array}{l}\text { reflected } \\
\text { sunlight }\end{array}$ & $\begin{array}{l}\text { glass } \\
\text { envelope }\end{array}$ & $\dot{q}_{\text {SolABs_g }}^{\prime}=\dot{q}_{i}^{\prime} \alpha_{g} K_{i}$ & \\
\hline$\dot{q}_{\text {SolAbs_a }}^{\prime}$ & & $\begin{array}{l}\text { Reflected } \\
\text { sunlight }\end{array}$ & Absorber tube & $\dot{q}_{\text {SolABS_a }}^{\prime}=\dot{q}_{i}^{\prime} \tau_{g} \alpha_{a} K_{i}$ & \\
\hline$\dot{q}_{\text {conv_g_air }}^{\prime}$ & convection & $\begin{array}{l}\text { outer } \text { glass } \\
\text { envelop } \\
\text { surface }\end{array}$ & ambient air & $\dot{q}_{\text {conv_g_air }}^{\prime}=\pi D_{g 2} h\left(T_{g 2}-T_{\infty}\right)$ & $\begin{array}{l}\text { (Chu 1975) } \\
\text { (J.P.Holman 1997) } \\
\text { P302-303 }\end{array}$ \\
\hline$\dot{q}_{\text {rad_g_sky }}^{\prime}$ & radiation & $\begin{array}{l}\text { outer } \text { glass } \\
\text { envelop } \\
\text { surface }\end{array}$ & sky & $\begin{array}{l}\dot{q}_{\text {rad_g_sky }}^{\prime}=\sigma A_{g 2} \varepsilon_{g 2}\left(T_{g 2}^{4}-T_{s k y}^{4}\right) \\
T_{s k y}=0.0552 T_{\infty}^{1.5}\end{array}$ & $\begin{array}{l}\text { (J.P.Holman 1997) P430 } \\
\text { (John A. Duffie 1980) P122 }\end{array}$ \\
\hline$\dot{q}_{\text {cond_sup }}^{\prime}$ & conduction & $\begin{array}{l}\text { outer absorber } \\
\text { tube surface }\end{array}$ & $\begin{array}{l}\text { Support } \\
\text { structure }\end{array}$ & $\dot{q}_{\text {cond_sup }}^{\prime}=\sqrt{\bar{h} P A k}\left(T_{\text {base }}-T_{\infty}\right)$ & $\begin{array}{l}\text { (J.P.Holman 1997) P46 } \\
\text { (Chu 1975) } \\
\text { (J.P.Holman 1997)P302-303 }\end{array}$ \\
\hline$\dot{q}_{\text {cond_g }}^{\prime}$ & conduction & $\begin{array}{l}\text { inner glass } \\
\text { envelope } \\
\text { surface }\end{array}$ & $\begin{array}{l}\text { outer glass } \\
\text { envelope } \\
\text { surface }\end{array}$ & $\dot{q}_{\text {cond }_{-} g}^{\prime}=\frac{2 \pi k\left(T_{g 1}-T_{g 2}\right)}{\ln \left(r_{g 2} / r_{g 1}\right)}$ & $\begin{array}{l}\text { (J.P.Holman 1997) } \\
\text { P30 }\end{array}$ \\
\hline$\dot{q}_{\text {conv_a_g }}^{\prime}$ & convection & $\begin{array}{l}\text { outer absorber } \\
\text { tube surface }\end{array}$ & $\begin{array}{l}\text { inner glass } \\
\text { envelope } \\
\text { surface }\end{array}$ & $\dot{q}_{\text {conv_a_g }}^{\prime}=\pi D_{a 2} h\left(T_{a 2}-T_{g 1}\right)$ & $\begin{array}{l}\text { (Vernon E. Dudley 1994) } \\
\text { P19 } \\
\text { (Frank P. Incropera 1990) }\end{array}$ \\
\hline$\dot{q}_{\text {rad_a_g }}^{\prime}$ & radiation & $\begin{array}{l}\text { outer absorber } \\
\text { tube surface }\end{array}$ & $\begin{array}{l}\text { inner glass } \\
\text { envelope } \\
\text { surface }\end{array}$ & $\dot{q}_{\text {rad_a_g }_{-}}^{\prime}=\frac{\sigma \pi D_{a 2}\left(T_{a 2}^{4}-T_{g 1}^{4}\right)}{\frac{1}{\varepsilon_{a 2}}+\frac{D_{a 2}}{D_{g 1}}\left(\frac{1}{\varepsilon_{g 1}}-1\right)}$ & (J.P.Holman 1997) P430 \\
\hline$\dot{q}_{\text {cond_a }}^{\prime}$ & conduction & $\begin{array}{l}\text { outer absorber } \\
\text { tube surface }\end{array}$ & $\begin{array}{l}\text { inner absorb } \\
\text { tube surface }\end{array}$ & $\dot{q}_{\text {cond_a }}^{\prime}=\frac{2 \pi k\left(T_{a 1}-T_{a 2}\right)}{\ln \left(r_{a 2} / r_{a 1}\right)}$ & $\begin{array}{l}\text { (J.P.Holman 1997) } \\
\text { P30 }\end{array}$ \\
\hline$\dot{q}_{\text {conv_fluid }}^{\prime}$ & convection & $\begin{array}{l}\text { inner absorber } \\
\text { tube surface }\end{array}$ & $\begin{array}{l}\text { heat transfer } \\
\text { fluid }\end{array}$ & $\dot{q}_{\text {conv_fluid }}^{\prime}=h \pi * D_{h}\left(T_{a 1}-T_{f}\right)$ & (J.P.Holman 1997) P289 \\
\hline
\end{tabular}

Parabolic Trough Solar Collector \& Piping

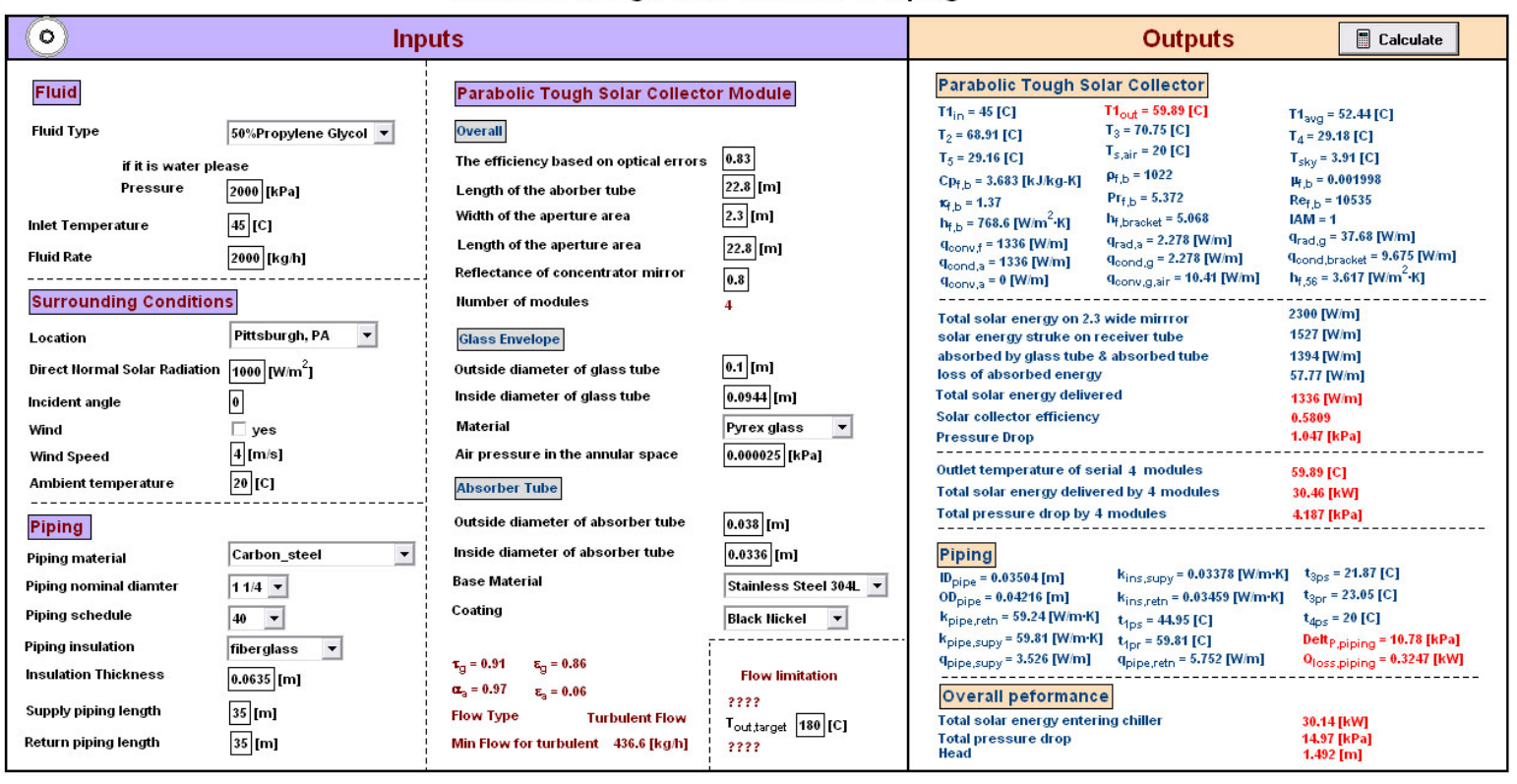

Fig. 7 Model interface 


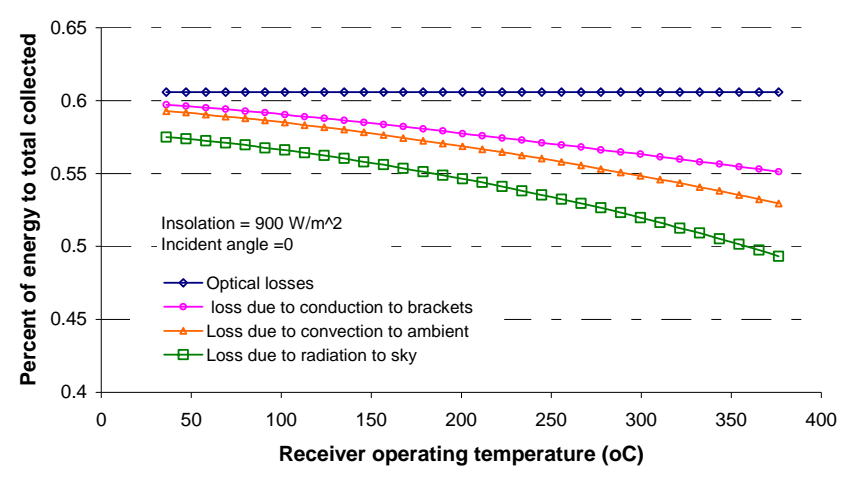

Fig. 8 The heat losses of an absorber tube

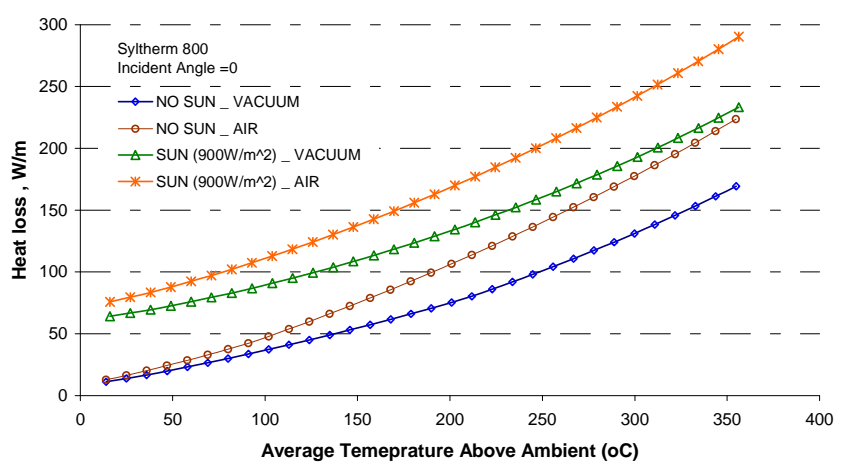

Fig. 9 The heat losses with sun or No sun

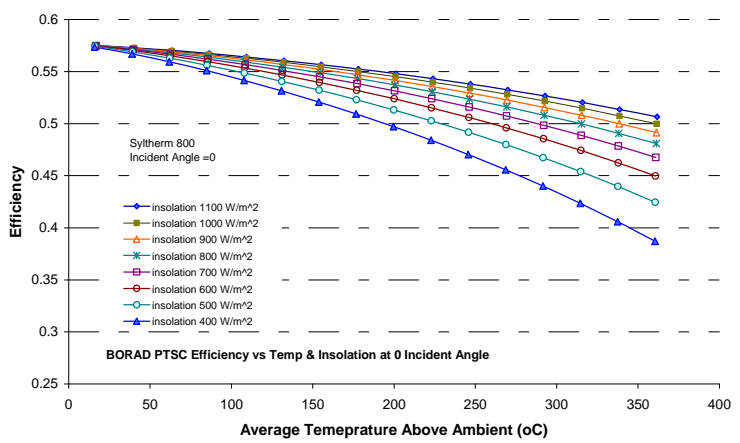

Fig. 10 PTSC efficiency and operating temperature

functions of the collector temperature. As you know, both the conduction and the convection have a linear relationship with the temperature and the radiation is the forth power of the collector temperature. Therefore increased collector operating temperature induces more thermal losses. Figure 10 shows that the collector efficiency drops with operating temperature increasing.

\subsection{PTSC Efficiency And Solar Insolation}

Solar collector absorbed more energy along with solar insolation increasing. Although the thermal losses also increase due to the increased collector temperature, it is much smaller than the enhanced absorbed solar energy. As shown in Figure10, PSTC efficiency increases with the solar insolation increasing.

\subsection{PTSC Efficiency And Incident Angle}

The incident angle modifier IAM is a very important factor impacting on the solar efficiency. The incident angle is the angle between the aperture normal and a central ray of the sun as shown in Figure 12. IAM is defined as the ration of the transmittance-absorptance product for angle of the incidence of radiation and for the normal incidence radiation. It is proximately equal to the cosine of the incident angle. It changes depending on the time of day, the day of the year, the location and orientation of the aperture, and whether it is stationary or tracks the sun movement about one or two axes. Collector efficiency is at a maximum only when the incident angle is zero. The efficiency of a PTSC decreases when the solar beam incident angle increases shown in Figure 11. The incident angle modifier is caused by cosine foreshortening of the collector aperture as well as other effects, such as the transmittance of glass envelope or the absorption of the selective surface as a function of incident angle. The end effect of incident angle is to reduce the insolation arriving at the absorber tube. Therefore at the noon time PTSC has the smallest incident angle and the highest collection efficiency. Figure 12 shows the PTSC Efficient has a significant drop, 17\%, down with 45 incident angle comparing to 0 incident angle.

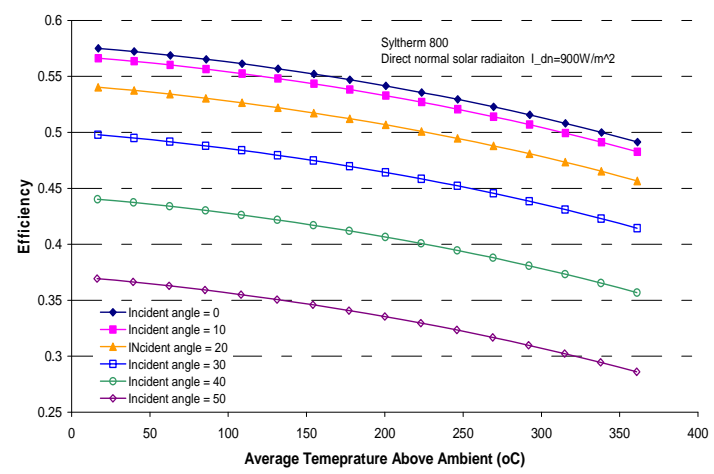

Fig. 11 PTSC efficiency and incident angle 


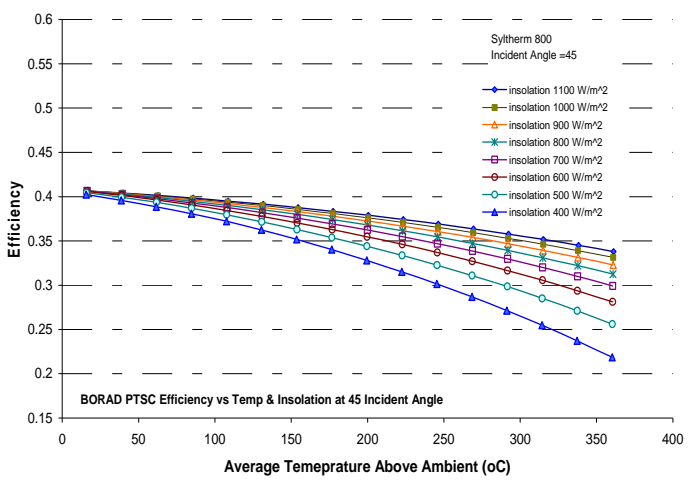

Fig. 12 PTSC efficiency with 45 incident angle

\subsection{PTSC Efficiency And Wind Speed}

The solar collector is exposed to the outside surrounding. Natural climate condition are at impacts its performance. Except solar radiation, wind speed is another import influent factor of the solar collector's performance. It not only impacts on the conduction loss to the supporting, but also on the convection loss from glass envelope to surrounding air. The PTSC efficiency reduces when the wind speed increases as indicated in Figure13

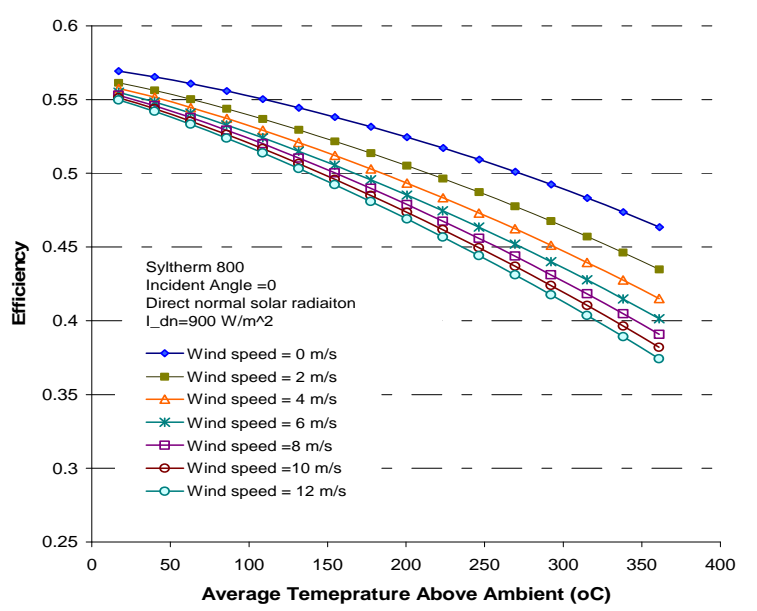

Fig. 13 PTSC efficiency and wind speed

\subsection{PTSC Efficiency And Fluid Type}

In order to find out whether the heat transfer fluid type influences the performance of the solar collector or not, six heat transfer fluids were selected to study how the fluid type impacts on the collector efficiency. Five heat transfer oil Syltherm 800, Dowtherm Q, Therminol 59, Therminol 66, Therminol XP, have few difference among them due to their similar thermal properties except water as shown in Figure 14. The trend shown here is related to the physical characteristic of the fluid.

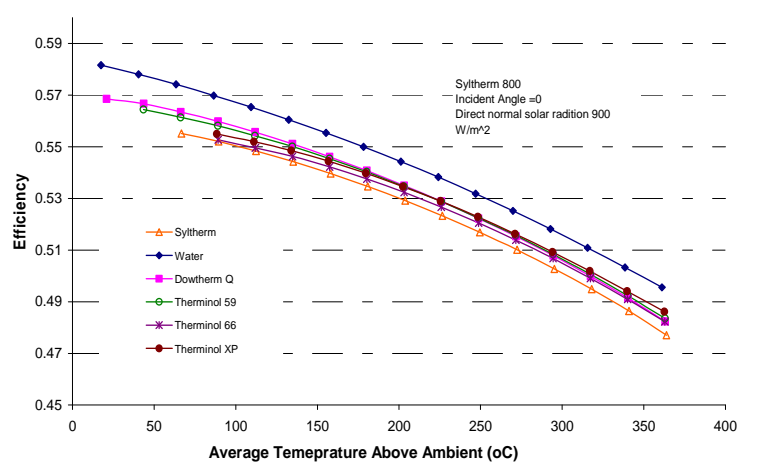

Fig. 14 PTSC efficiency and flow rate

\subsection{PTSC Efficiency And Flow Rate}

Eight calculated results under different flow rate show that flow rate does not impact on the PTSC performance as shown in Figure 15.

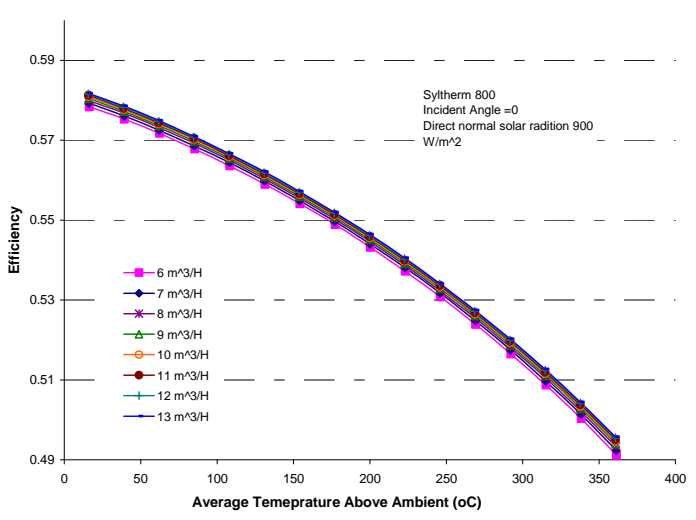

Fig. 15 PTSC efficiency and flow rate

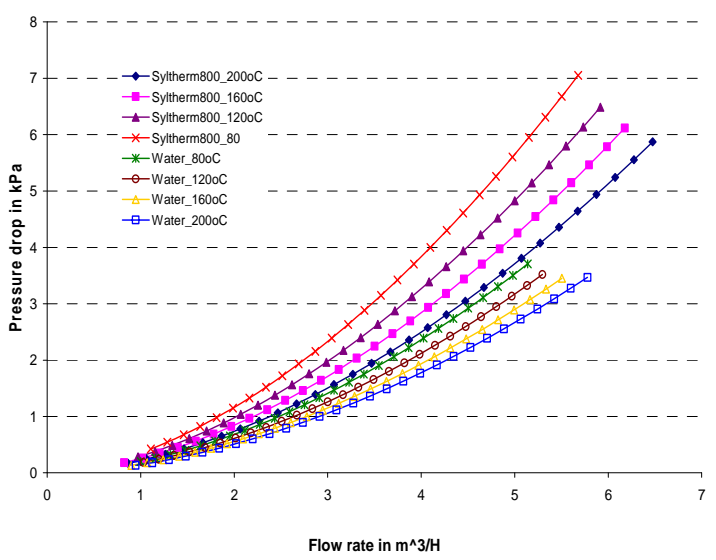

Fig. 16 PTSC pressure drop

\subsection{Pressure Drop Along The Receiver}

In addition, the PTSC model also provides the pressure drop along the absorber tube. For 5.7meter long, heat transfer oil like syltherm 800 , which has a 
higher viscosity, has a higher pressure drop than water as shown in Figure 16. With the operating temperature increasing, the pressure drop decreases because the viscosity of fluid reduces.

\subsection{PTSC Efficiency And Air}

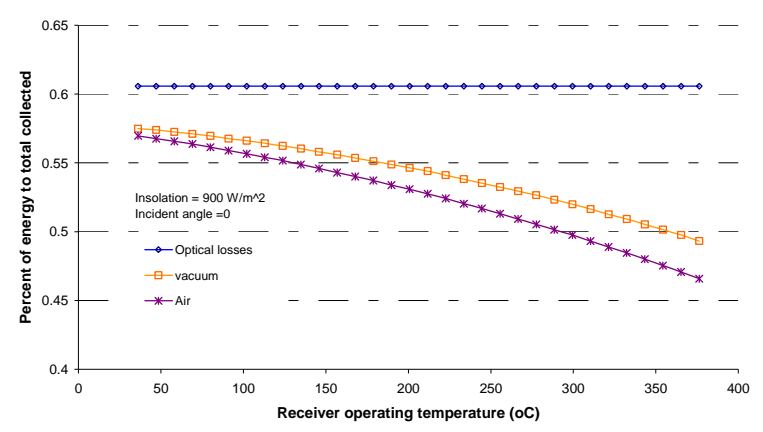

Fig. 17 the PTSC efficiency and air in annular

When a vacuum is present in the annulus between the receiver surface and the glass envelope, the conduction and the convection across the annulus are effectively eliminated. Once air is introduced into the vacuum space, measured losses increase significantly since conduction and convection begin to transfer heat to the glass envelope as shown in Figure 17. Radiation loss from the heated receiver's metal surface to the glass envelope is not changed very much by the presence of air in the annulus.

\subsection{PTSC Efficiency And Glass Cover}

Surface temperature of the glass is significantly lower than the receiver's metal surface. If the glass envelope is removed, conduction and convection losses to the ambient air will be greatly enhanced, and wind effects will be much larger. Radiation losses will also increase when glass is removed because the higher temperature metal surface now radiate directly to the sky.

\subsection{PTSC Efficiency Simplified Equation}

To derive a performance equation of PTSC for simulation tool like TRNSYS, a multiple linear regression of calculated collector efficiency was implemented over the range of insolation from zero to $1100 \mathrm{w} / \mathrm{m}^{\wedge} 2$, and temperature from ambient to $400 \mathrm{C}$ to produce the performance equation of efficiency, shown in equation 12 . Statistic parameters, $\mathrm{s}$ and $\mathrm{R}-\mathrm{Sq}$, show that the regression describe the relation very well because residual mean square error $\mathrm{S}$ is equal to a very small value 0.000335664 and fraction of the variability $\mathrm{R}^{\wedge} 2$ is 0.999 .

$\eta=0.577 K-0.0958(\delta T / I)-0.000318\left(\delta T^{2} / I\right)$

The equation is one of standard collector's efficiency presented forms. Although this form does not present the correlation of efficiency and thermal loss, as you know, radiation loss is proportional to the forth power of $\delta T$ temperature difference, it could relative accurately represent the performance and it is useful.

\section{CONCLUSION}

As a mathematical tool, the developed heat transfer and mass balance PTSC model is very useful for solar heating and cooling system design. It not only helps to select the proper operating conditions and to detect the possible problems in the design of system, but also provides some basic figures for device's selection like pump as well. The model will be further used now to optimize design parameters and operating conditions of solar cooling and heating system for Intelligent Workplace (IW) at Carnegie Mellon University (CMU) in Pittsburgh.

\section{FUTURE WORK}

Currently, Carnegie Mellon University has installed the PTSC based solar heating and cooling system as a pioneer of the high-temperature solar energy supply system for building usage. When the experimental data is acquired, the model will be validated. Then the calculated results will be used to do system simulation.

In parallel, the model will be used to improve PTSC design. The final PTSC optimal design will be send back to the provider, BROAD, to improve the product performance.

\section{REFERENCES}


[1]Chu, S. W. C. a. H. H. S. (1975). "Correlation equations for laminar and turbulent free convection from a horizontal cylinder." Int. J. Heat Mass Transfer 18: 1049 .

[2]Frank P. Incropera, d. P. d. w. (1990). Fundamentals of heat and mass transfer, John wiley \& Sons, Inc.

[3]J.P.Holman (1997). Heat Transfer. New York, McGRAW-HILL,INC.
[4]John A. Duffie, W. A. B., Solar Energy laboratory (1980). Solar Engineering of Thermal Processes. New York, John Wiley \& Sons.

[5]Vernon E. Dudley, G. J. K., Michael Sloan, David Kearney (1994). Test results SEGS LS-2 Solar Collector. 